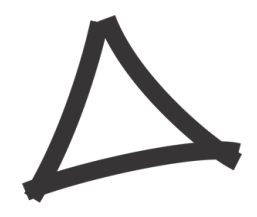

Revista Triângulo

www.seer.uftm.edu.br/revistaeletronica

(9) $\Theta \Theta$

\title{
CURRÍCULO DO CURSO DE LICENCIATURA EM MATEMÁTICA E FORMAÇÃO DE PROFESSORES NA ANPED - 2005 A 2015
}

\author{
CURRICULUM OF THE UNDERGRADUATE COURSE IN MATHEMATICS AND TEACHERS \\ EDUCATION IN THE ANPED - 2005 TO 2015
}
CURRICULO DEL CURSO DE LICENCIATURA EN MATEMÁTICA Y LA FORMACIÓN DE PROFESORES EN LA ANPED- 2005 A 2015

\author{
Marina Machado \\ E-mail: marinamachado02@,hotmail.com \\ Roberta Costa \\ E-mail: roberta.costa@uberabadigital.com.br \\ Martha Maria Prata Linhares \\ E-mail: martha.prata@gmail.com \\ Universidade Federal do Triângulo Mineiro - UFTM \\ Agência de fomento: FAPEMIG
}

\begin{abstract}
RESUMO
Este estudo teve por objetivo levantar a produção intelectual da área da educação relacionada ao currículo do curso de Licenciatura em Matemática e formação de professores nos artigos publicados nos anais das reuniões da Associação Nacional de Pós-Graduação e Pesquisa em Educação (Anped) de 2005 a 2015 nos Grupos de Trabalho: Formação de Professores, Currículo e Educação Matemática. Utilizou-se a metodologia de análise documental e determinou-se três descritores: formação de professores; matemática; e currículo. De um total de 608 trabalhos publicados, 83 foram desconsiderados por não terem os resumos disponíveis on line no ano de 2005 , restando 525 artigos que desses, apenas 11 encontrou-se os três descritores. Os resultados indicam que os trabalhos envolvendo os três descritores ocupam pouco espaço nas produções encontradas na Anped Nacional. Esse fato aponta para uma possível lacuna na exploração do currículo do curso de Licenciatura em Matemática e formação de professores.
\end{abstract}

PALAVRAS-CHAVE: Currículo. Matemática. Formação de professores.

\begin{abstract}
This study aimed to investigate the intellectual production of education related to the curriculum of the undergraduate course in Mathematics and teacher education in the articles published in the National Association of Postgraduate and Research in Education (Anped) on line conference proceedings from 2005 to 2015 in the working groups: Teacher Education, Curriculum and Mathematical Education. The methodological approach included bibliographical and documental. In the collected data three descriptors were determined: teacher education; mathematics; and curriculum. Of a total of 608 papers published, 83 were disregarded because abstracts were not available in 2005 , with 525 articles remaining, of which only 11 were the three descriptors. The results indicated that the articles involving the three descriptors occupy little space in the productions found in the National Anped. This fact indicates a lag in the exploration of the curriculum of the degree course in Mathematics and teacher education.
\end{abstract}

KEYWORDS: Curriculum. Mathematics. Teacher education.

\section{RESUMEN}

Este estudio tuvo por objetivo levantar la producción intelectual del área de la educación relacionada al currículo del curso de Licenciatura en Matemática y formación de profesores en los artículos publicados en los anales de las reuniones de la Asociación Nacional de Postgrado e Investigación en Educación (Anped) de 2005 a 
2015 en los grupos de trabajo: GT08, GT12 y GT19. Se utilizó la metodología de análisis documental y se determinó tres descriptores: formación de profesores; matemáticas; y el currículo. De un total de 608 trabajos publicados, 83 fueron desconsiderados por no tener los resúmenes disponibles en el año 2005, restando 525 artículos que de ellos, sólo 11 se encontraron los tres descriptores. Se concluye que los trabajos involucrando a los tres descriptores ocupan poco espacio en las producciones encontradas en la Anped Nacional. Este hecho apunta un desfase en la exploración del currículo del curso de Licenciatura en Matemáticas y formación de profesores.

PALABRAS-CLAVE: Plan de estudios. Matemáticas. Formación de profesores.

\section{INTRODUÇÃO}

A Lei de Diretrizes e Bases 9394/96 (LDB), Brasil (1996), em seu artigo 43, retrata a finalidade da educação superior, visando estimular o desenvolvimento do espírito científico e reflexivo, além de incentivar o trabalho de pesquisa e a investigação científica e tecnológica. O artigo 61 refere-se à formação dos profissionais da educação e tem como fundamento uma formação sólida que propicie conhecimentos científicos, competências para o trabalho e a associação entre teoria e prática, levando em conta, a experiência adquirida.

Freire (1996, p.28), analisando as questões relacionadas à docência, destaca:

Rigorosidade metódica, pesquisa, respeito aos saberes dos educandos, criticidade, ética e estética, corporificar as palavras pelo exemplo, assumir riscos, aceitar o novo, rejeitar qualquer forma de discriminação, reflexão crítica sobre a prática, reconhecimento e assunção da identidade cultural, ter consciência do inacabamento, reconhecer-se como um ser condicionado, respeitar a autonomia do ser educando, bom senso, humildade, tolerância, convicção de que mudar é possível, curiosidade, competência profissional.

O autor descreve a finalidade e a imprescindibilidade da docência em sua prática, assim como os Parâmetros Curriculares Nacionais (PCN), que considera a formação inicial do professor sendo um processo contínuo e sistemático que o leva a refletir sobre sua prática, justificando que a “[...] formação não pode ser tratada como um acúmulo de cursos e técnicas, mas sim como um processo reflexivo e crítico sobre a prática educativa" (BRASIL, 1997, p. 25).

Nessa perspectiva, Masetto (2004, p. 187) ressalta a importância de criar uma aproximação entre os conteúdos e o universo da cultura, a valorização das contextualizações e a busca permanente de uma instrumentação crítica para o mundo do trabalho ao explicar que na formação de professores "na maioria das vezes as discussões e debates se passa para remendos na grade curricular ou nas cargas horárias dos 


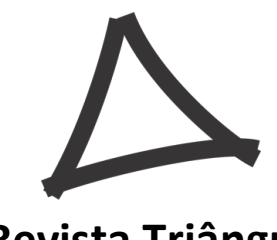

Revista Triângulo

www.seer.uftm.edu.br/revistaeletronica

departamentos e dos professores e continuamos na mesma situação de insatisfação, desconforto, desinteresse e desmotivação".

Feldmann, Masetto e Freitas (2016) mostram que há décadas, o currículo vem sendo compreendido como uma grade de conteúdo estático, com objetivo técnico, contemplativo, sempre se concretizando em um sentido de linearidade sendo desenvolvido em um determinado período. Embora o currículo seja compreendido desta forma por muitos profissionais da Educação, podemos observá-lo através da perspectiva de Masetto (2014, p. 406), que aponta o currículo "como prática social pedagógica [...], como um ordenamento sistêmico formal no tempo e no espaço, de ações coletivas e individuais de aprendizagem". Essa perspectiva sugere ao professor elencar o currículo, os conteúdos, o educando e a busca permanente por saberes significativos, da mesma forma que o currículo necessita integrar o trabalho pedagógico curricular, a teoria e o contexto escolar (FREITAS, 2016).

Pensando no currículo de Matemática, Smole e Diniz (2001) defendem que propostas que objetivem uma aprendizagem significativa em Matemática devem abordar uma variedade de ideias matemáticas, sejam numéricas, geométricas, relativas às medidas e às noções de estatística, entre outras, de modo que seja proporcionado ao aluno diferentes formas de perceber a realidade e o conhecimento matemático. Além disso, a predominância do silêncio, no sentido de ausência de comunicação, ainda é comum nas aulas desta disciplina. $\mathrm{O}$ excesso de cálculos mecânicos, a ênfase em procedimentos e a linguagem usada para ensinar Matemática são alguns dos fatores que tornam a comunicação pouco frequente ou quase inexistente.

Os PCN sugerem aos professores que instiguem os alunos a observar os fenômenos, conjeturar hipóteses, fazer levantamento de dados, tratá-los e analisá-los do ponto de vista da investigação científica (Brasil, 1997). Também incentivam a leitura e a interpretação de gráficos, de tabelas e de medidas publicadas pelos diversos meios de comunicação, a fim de que o aluno saiba posicionar-se de forma crítica diante dessas informações e fornecer-lhes ferramentas para arguir e "desmantelar" informações porventura falaciosas ou mal-intencionadas (LOPES; COUTINHO; ALMOULOUD, 2010). 


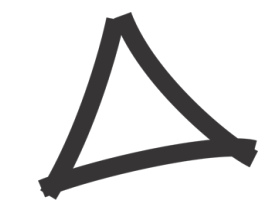

Portanto, refletindo sobre essa perspectiva, o objetivo desta pesquisa foi investigar o quanto pesquisadores da área de Educação tem explorado a importância que envolve o currículo do curso de Licenciatura em Matemática e formação de professores.

\section{MATERIAIS E MÉTODOS}

O estudo tem como propósito a construção de uma investigação bibliográfica que se aproxima do Estado da Arte para educação. Fizemos uma análise documental e descritiva das produções científicas sobre o currículo do curso de Licenciatura em Matemática e formação de professores. Optamos por esse método por se tratar "de um instrumento que busca a compreensão do conhecimento sobre determinado tema, em um período de tempo específico e, consequentemente sua sistematização e análise". (TEIXEIRA, 2006, P. 60).

Para a realização do estudo, utilizamos um método misto de pesquisa; qualitativa, que visa compreender e classificar os processos dinâmicos vividos em um determinado grupo; e quantitativa, porque utilizaremos técnicas estatísticas, objetivando resultados que evitem possíveis distorções de análise e interpretação, possibilitando uma maior margem de segurança, de acordo com o que expõe Diehl (2004). A dimensão qualitativa da pesquisa foi realizada por meio de uma revisão bibliográfica das produções acadêmicas da área da Educação em relação ao currículo do curso de Licenciatura em Matemática e formação de professores. Essa revisão foi composta por artigos publicados nos anais das reuniões da Associação Nacional de Pós-Graduação e Pesquisa em Educação (Anped) de 2005 a 2015 nos Grupos de Trabalho (GTs): GT08 - Formação de Professores, GT12 Currículo e GT19 - Educação Matemática.

A pesquisa foi iniciada a partir da nossa área de atuação e de interesse. Com isso, chegamos aos três descritores: "formação de professores", "matemática" e "currículo". O primeiro critério para seleção dos artigos foi encontrar os três descritores no título dos textos, e não houve nenhum artigo encontrado. Na etapa posterior buscamos os três descritores como palavras-chave nos artigos publicados, e também não encontramos nenhum artigo. Para finalizar, a terceira etapa foi buscar os três descritores no resumo dos artigos, cujo retorno foi de 11 artigos no período de 2006 a 2015. Como no ano de 2005 os resumos não estavam disponíveis no site da Anped Nacional, somente olhamos os resumos a partir de 2006. 
A análise foi feita com base nas informações contidas nos resumos dos artigos e criamos categorias de análise que sistematizassem as informações: (i) Formação de professores em uma área específica de Matemática; (ii) Análise sobre formação de professores; (iii) Práticas pedagógicas com uso de tecnologias; (iv) Fatos evidenciados durante formação/ estágio; (v) Percurso histórico.

\section{ANÁLISE DOS DADOS E RESULTADO}

O quadro 1 apresenta os números levantados sobre os artigos publicados na Anped Nacional no período de 2005 a 2015:

Quadro 1. Artigos publicados na área da educação, com os três descritores de 2005 a 2015:

\begin{tabular}{|c|c|c|c|c|c|c|c|c|c|c|c|}
\hline & $28^{2}$ & $29^{2}$ & $30^{2}$ & $31^{2}$ & $32^{2}$ & $33^{2}$ & $34^{2}$ & $35^{2}$ & $36^{2}$ & $37^{2}$ & \multirow{2}{*}{$\begin{array}{l}\text { Total } \\
\text { Gera }\end{array}$} \\
\hline & 2005 & 2006 & 2007 & 2008 & 2009 & 2010 & 2011 & 2012 & 2013 & 2015 & \\
\hline $\begin{array}{l}\text { GT 8 - Formação de } \\
\text { Professores }\end{array}$ & 45 & 29 & 31 & 18 & 21 & 21 & 22 & 22 & 18 & 23 & \\
\hline $\begin{array}{l}\text { GT \& - Formação de } \\
\text { Professores } \\
\text { excedentes }\end{array}$ & 0 & 0 & 0 & 0 & 0 & 0 & 0 & 0 & 0 & 13 & \\
\hline GT 12 - Currículo & 18 & 11 & 15 & 17 & 17 & 18 & 29 & 15 & 18 & 22 & \\
\hline $\begin{array}{l}\text { GT } 12-\text { Currículo- } \\
\text { excedentes }\end{array}$ & 0 & 0 & 0 & 0 & 0 & 0 & 0 & 0 & 0 & 4 & \\
\hline $\begin{array}{l}\text { GT } 19 \text { - Educação } \\
\text { Matemática }\end{array}$ & 19 & 20 & 15 & 16 & 10 & 18 & 15 & 12 & 20 & 15 & \\
\hline $\begin{array}{l}\text { GT } 19 \text { - Educação } \\
\text { Matemática } \\
\text { excedentes }\end{array}$ & 0 & 0 & 0 & 0 & 0 & 0 & 0 & 0 & 0 & 0 & \\
\hline $\begin{array}{l}\text { Arquivos que não } \\
\text { abrem }\end{array}$ & 1 & 0 & 0 & 0 & 0 & 0 & 0 & 0 & 0 & 0 & \\
\hline Total & 83 & 60 & 61 & 51 & 48 & 57 & 66 & 49 & 56 & 77 & 608 \\
\hline
\end{tabular}

Os resultados indicam que de um total de 608 trabalhos publicados de 2005 a 2015 na Anped Nacional, 83 foram desconsiderados, por não terem os resumos disponíveis no site oficial da Anped Nacional relacionados aos trabalhos do ano de 2005, restando, portanto, 525 artigos que desses, apenas em 11 encontramos os três descritores, sendo 01 publicado no ano de 2007, 01 no ano de 2009, 05 publicados no ano de 2010, 01 no ano de 2013 e 03 publicados no ano de 2015 , ou seja, 1,81\% do total das produções publicadas. 
Quadro 2. Artigos publicados na Anped Nacional, separados por ano de publicação, com os três descritores de 2006 a 2015:

\begin{tabular}{|l|l|l|l|l|l|l|l|l|l|l|}
\hline Ano & 2006 & 2007 & 2008 & 2009 & 2010 & 2011 & 2012 & 2013 & 2015 & Total \\
\hline Quant. & 0 & 1 & 0 & 1 & 5 & 0 & 0 & 1 & 3 & 11 \\
\hline
\end{tabular}

Fonte: Das organizadoras, 2017.

No quadro 3 apresentamos o número de publicações encontradas de 2006 a 2015, com relação ao GTs.

Quadro 3. Artigos publicados na Anped Nacional, separados por GT de publicação, com os três descritores de 2006 a 2015:

\begin{tabular}{|l|l|l|l|}
\hline Ano & GT 08 & GT12 & GT19 \\
\hline 2006 & 0 & 0 & 0 \\
\hline 2007 & 0 & 0 & 1 \\
\hline 2008 & 0 & 0 & 0 \\
\hline 2009 & 0 & 0 & 1 \\
\hline 2010 & 2 & 0 & 3 \\
\hline 2011 & 0 & 0 & 0 \\
\hline 2012 & 0 & 0 & 0 \\
\hline 2013 & 0 & 0 & 1 \\
\hline 2015 & 0 & 0 & 3 \\
\hline TOTAL & 2 & 0 & 9 \\
\hline
\end{tabular}

Fonte: Das organizadoras, 2017.

No quadro 3, podemos perceber que o GT 19 - Educação Matemática, apresenta nove artigos publicados na Anped Nacional no período de 2006 a 2015, enquanto que o GT 08 - Formação de Professores, consta de apenas dois artigos publicados, enquanto que o GT 12 - Currículo, não possui nenhum artigo publicado, que tenha os três descritores: formação de professores, currículo e matemática, presentes em seus títulos, palavraschave ou resumo. Esses dados podem ser relacionados a alguns fatores, como por exemplo, os três descritores, tem atraído pouco a atenção dos pesquisadores da área da Educação, sobre o currículo a ser trabalhado e a Matemática a ser estudada nos cursos superiores, voltados para a formação de professores. Assim, concordamos com Freitas 
(2013), "ainda temos diversas áreas que carecem dessa atenção nas pesquisas que apontem o já elaborado, os enfoques e as lacunas existentes" (p. 87, 88).

Dentre as publicações relacionadas os três descritores estão nos seguintes artigos:

Quadro 4. Artigos publicados na Anped Nacional, separados por ordem alfabética de autoria, com os três descritores, no resumo dos artigos no período de 2006 a 2015: 


\begin{tabular}{|c|c|c|c|c|}
\hline Autoria & Título & GT & $\begin{array}{l}\text { Tipo e ano } \\
\text { de } \\
\text { publicação }\end{array}$ & Palavras-chave \\
\hline CARNEIRO, R. F. & $\begin{array}{l}\text { Narrativas no estágio } \\
\text { supervisionado em matemática } \\
\text { como uma possibilidade para } \\
\text { discussão da profissão docente. }\end{array}$ & GT 19 & Artigo/ 2015 & $\begin{array}{l}\text { Narrativas. Formação de } \\
\text { profes sores. Estágio em } \\
\text { matemática. }\end{array}$ \\
\hline COSTA, V. G. & $\begin{array}{l}\text { Somos uma geração que tem sede } \\
\text { de viver as oportunidades, mas se } \\
\text { nós não paramos, a vida nos faz } \\
\text { parar: A história da constituição de } \\
\text { Ana como formadora de } \\
\text { professores de matemática. }\end{array}$ & GT 19 & Artigo/ 2010 & $\begin{array}{lr}\text { Professor } & \text { formador. } \\
\text { Licenciatura em } & \text { Matemática. } \\
\text { Profissionalidade. } & \\
\text { Intensificação, } & \text { trabalho } \\
\text { docente. } & \end{array}$ \\
\hline FERREIRA, A. C. & $\begin{array}{l}\text { A formação de professores de } \\
\text { matemática em Minas Gerais: O } \\
\text { caso da Faculdade de Filos ofia, } \\
\text { Ciências e Letras de Minas Gerais. }\end{array}$ & GT 19 & Artigo/ 2010 & $\begin{array}{l}\text { Licenciatura em Matemática. } \\
\text { Estudo histórico. Faculdade } \\
\text { de Filos ofia. Ciências e Letras } \\
\text { de Minas Gerais. }\end{array}$ \\
\hline $\begin{array}{l}\text { FERREIRA, V. L.; PASSOS, } \\
\text { L. F. }\end{array}$ & $\mid \begin{array}{lrr}\text { O percurso } & \text { histórico da } \\
\text { metodologia do ensino de } & \text { de } \\
\text { matemática no curso de Pedagogia. }\end{array}$ & GT 19 & Artigo/ 2013 & $\begin{array}{l}\text { Curso de } \\
\text { Formação de professores. } \\
\text { História do currículo. História } \\
\text { da educação Matemática. } \\
\text { Metodologia do Ensino de } \\
\text { Matemática. }\end{array}$ \\
\hline GENTIL, H. S. & $\begin{array}{l}\text { Formação de professores na } \\
\text { perspectiva de docentes dos cursos } \\
\text { de Pedagogia da UNEMAT/ } \\
\text { CÁCERES e SINOP. }\end{array}$ & GT 08 & Artigo/ 2010 & Não informado. \\
\hline LOPES, C. E. & $\begin{array}{l}\text { A educação estatística no currículo } \\
\text { de matemática: um ensaio teórico. }\end{array}$ & GT 19 & Artigo/ 2010 & Não informado. \\
\hline LOPES, R. P.; FÜRKOTTER, & $\begin{array}{l}\text { Formação para o uso das } \\
\text { tecnologias digitais de informação e } \\
\text { comunicação (TDIC) nas } \\
\text { licenciaturas presenciais das } \\
\text { Universidades Estaduais Paulistas. }\end{array}$ & GT 08 & Artigo/ 2010 & 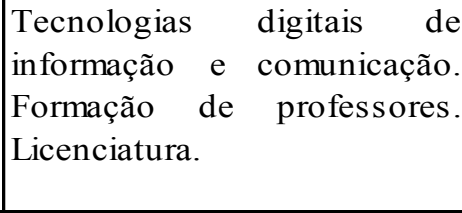 \\
\hline $\begin{array}{l}\text { MUNIZ, C. A.; COSTA, E. } \\
\text { S.; SILVA, } \quad \text { E. } \quad \text { B.; } \\
\text { CARVALHO, R. P. }\end{array}$ & $\begin{array}{l}\text { Profess ora Nilza Eigenheer Bertoni: } \\
\text { Sua contribuição para o } \\
\text { desenvolvimento da educação } \\
\text { matemática no Distrito Federal e no } \\
\text { Brasil }\end{array}$ & GT 19 & Artigo/ 2009 & $\begin{array}{ll}\text { Educação. } & \text { Matemática. } \\
\text { Distrito Federal. } & \end{array}$ \\
\hline $\begin{array}{l}\text { OLIVEIRA, A. T. C. C.; } \\
\text { FIORENTINI, D. }\end{array}$ & $\begin{array}{l}\text { O papel e o lugar da didática } \\
\text { específica na formação inicial do } \\
\text { professor de matemática. }\end{array}$ & GT 19 & Artigo/ 2015 & $\begin{array}{l}\text { Didática } \begin{array}{lr}\text { especial. Formação } \\
\text { inicial. } \\
\text { Matemática. }\end{array} \\
\text { Licenciatura em } \\
\end{array}$ \\
\hline RESENDE, M. R. & $\begin{array}{|lcr|}\text { Re-significando a disciplina Teoria } \\
\text { dos Números na formação do } \\
\text { professor de matemática na } \\
\text { Licenciatura. }\end{array}$ & GT 19 & Artigo/ 2007 & Não informado. \\
\hline $\begin{array}{l}\text { SILVA, M. M.; CEDRO, W. } \\
\text { L. }\end{array}$ & $\begin{array}{l}\text { O planejamento compartilhado das } \\
\text { ações pedagógicas: a aprendizagem } \\
\text { da docência do professor de } \\
\text { matemática. }\end{array}$ & GT 19 & Artigo/ 2015 & $\begin{array}{l}\text { Aprendizagem da docência } \\
\text { em Matemática. Planejamento } \\
\text { compartilhado. Organização } \\
\text { do ensino. }\end{array}$ \\
\hline
\end{tabular}




\subsection{Formação de professores em uma área específica de Matemática}

Nesta categoria, encontramos dois artigos:

a) Resende (2009) com o título Re-significando a disciplina Teoria dos Números na formação do professor de matemática na licenciatura.

A autora teve como objeto de estudo a disciplina Teoria dos Números no curso de Licenciatura em Matemática e procurou desvelar, a partir de algumas fontes históricas, como é a formação do professor que irá atuar no Ensino Fundamental e Médio. Nesse artigo percebemos a preocupação com o tema de estudo ainda pouco explorado na Educação Matemática e referente aos saberes específicos que devem fazer parte do currículo da licenciatura.

b) Lopes (2010) intitulado A educação estatística no currículo de matemática: um ensaio teórico.

Nesta pesquisa a autora ressalta a importância da formação didática pedagógica do futuro professor de matemática da Educação Básica ao se trabalhar a análise combinatória, a probabilidade e a estatística. Reforçando que a estatística ajuda na compreensão das características da sociedade, facilita na tomada de decisões e é uma ciência de análise de dados. Defende um ensino de estatística e probabilidade voltado para a problematização.

Lopes, ainda sugere que os professores de matemática, devem aproveitar os interesses reais dos alunos para coletar e organizar os conjuntos de dados, visando promover atividades interdisciplinares e intradisciplinares.

\subsection{Análise sobre formação de professores}

Para esta categoria, encontramos quatro artigos:

a) Ferreira (2010, p.16) questiona "qual é a realidade das salas de aula? Conseguimos incorporar lições do passado ou continuamos reproduzindo aulas da década de 1950 e 1960?", referindo-se a esse trecho a autora afirma que "um estudo do passado pode nos auxiliar a iluminar nosso presente e a buscar elementos para construir um futuro mais próximo da formação de professores de Matemática que almejamos", apontando principalmente a primeira Licenciatura em Matemática, apresentando ainda, a formação do professor de Matemática na FFCLMG. 


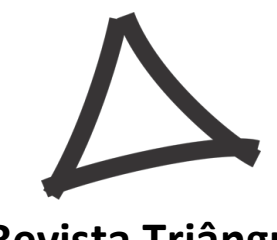

Revista Triângulo

www.seer.uftm.edu.br/revistaeletronica

b) Gentil (2013) com o título Formação de professores na perspectiva de docentes dos cursos de pedagogia da UNEMAT/ CÁCERES e SINOP salientando inquietudes sobre a formação oferecida pelo curso e sobre qual é o pensamento do professor de ensino superior referente a sua formação.

c) Costa (2010) com o título Somos uma geração que tem sede de viver as oportunidades, mas se nós não paramos, a vida nos faz parar: a história da constituição de Ana como formadora de professores de Matemática, foi o quarto trabalho encontrado, também no GT 19 (Educação Matemática). Nesta pesquisa percebemos como objetivo o trabalho dos professores formadores que atuam nos cursos de Licenciatura em Matemática do estado de Minas Gerais.

De acordo com Costa (2010, p.3), ainda é tímida a temática sobre formação inicial de professores: apesar da existência de um número significativo de pesquisas sobre a formação inicial de professores, até meados da metade dos anos 2000, o tema professor formador era silenciado. Nos três últimos anos, nos encontros anuais da ANPED, a temática tem aparecido nas pesquisas, mas ainda de forma tímida. Também aparece no estudo comparativo sobre a produção das dissertações e teses sobre formação de professores no Brasil, nos anos de 1993 e 2003.

A autora ressalta ainda, que o professor formador precisa repensar sua prática, se modificar, modificar o outro e promover a própria compreensão de seu trabalho, que é também uma prática formativa, solitária e individual, além de ter uma sobrecarga. Aponta que há pouca ligação entre a universidade, a instituição de ensino superior e a escola.

d) Oliveira e Fiorentini (2015), com o título O papel e o lugar da didática específica na formação inicial do professor de Matemática. Neste artigo notamos que os autores se interessam pela formação didático pedagógica do futuro professor de matemática e trazem algumas questões decorrentes de uma pesquisa focada no estudo da disciplinas de Didática Especial de Matemática comumente presentes nos currículos dos cursos de Licenciatura em Matemática.

\subsection{Práticas pedagógicas com uso de tecnologias}

Para esta categoria, encontramos apenas um artigo. 
a) Lopes e Fürkotter (2010) realizaram uma pesquisa questionando a utilização das TDIC na formação de professores da Educação Básica. Concluíram que todas as 124 licenciaturas pesquisadas contemplam em seu currículo disciplinas obrigatórias e optativas, que abordem o uso das TDIC. Além disso, dos seis projetos pedagógicos analisados no trabalho, apenas o de Matemática apresenta proposta de formação para o uso das TDIC na educação básica.

\subsection{Fatos evidenciados durante formação/ estágio}

Para esta categoria, encontramos dois artigos:

a) Carneiro (2015) intitulado Narrativas no Estágio Supervisionado em Matemática como uma possibilidade para discussão da profissão docente. O autor utilizou uma pesquisa qualitativa com o intuito de refletir sobre a profissão docente através de narrativas relatadas por futuros professores durante a realização do estágio em Matemática.

b) Silva e Cedro (2015) com o título O planejamento compartilhado das ações pedagógicas: a aprendizagem da docência do professor de Matemática. Os autores tiveram como objetivo entender as mudanças ocasionadas por uma proposta de aprendizagem da docência. Os principais resultados apontados pelos autores foram que um processo de organização de ações docentes modificou e causou modificações na aprendizagem de conteúdos matemáticos.

\subsection{Percurso histórico}

Para esta categoria, encontramos dois artigos:

a) Munizet al (2009), com o título Professora Nilza Eigenheer Bertoni: sua contribuição para o desenvolvimento da educação matemática no Distrito Federal e no Brasil.

Os autores evidenciam a professora Nilza Eigenheer Bertoni como referência por sua atuação ativa diante a educação matemática no Brasil, devido sua busca por mudanças no currículo da Licenciatura de Matemática e principalmente por sua inserção na educação do Distrito Federal desde 1970, atuando no Departamento de Matemática da Universidade de Brasília, onde desenvolveu um trabalho de pesquisa interventiva na educação básica do DF. 
b) Ferreira e Passos (2013), com o título O percurso histórico da metodologia do ensino de matemática no curso de Pedagogia.

Os autores tiveram por objetivo analisar o percurso da disciplina de Metodologia do Ensino de Matemática nos cursos de Pedagogia de 1939 a 1999, considerando os currículos das instituições de ensino superior do estado de São Paulo: USP Universidade de São Paulo, PUC/ SP - Pontifícia Universidade Católica de São Paulo e UNICAMP - Universidade Estadual de Campinas.

Analisando os dados observamos que nos demais trabalhos existem pouca incidência da temática sobre o currículo do curso de Licenciatura em Matemática e formação de professores. Os descritores aparecem nas palavras-chave, no entanto não fazem referência ao tema deste trabalho. Apresentam ideias diluídas, ambíguas, ou até mesmo fragmentadas em relação à reflexão a que se propõe.

\section{CONSIDERAÇÕES FINAIS}

Diante da presente análise do mapeamento e discussão da produção da área da Educação nos trabalhos da Anped no período 2005 a 2015, relacionada ao currículo do curso de Licenciatura em Matemática e formação de professores, concluímos que os trabalhos envolvendo esses três descritores, ocupam muito pouco espaço nas produções encontradas na Anped Nacional. Outro aspecto importante é que a maioria dos trabalhos publicados são encontrados no GT 19 - Educação Matemática. Também observamos a limitação da discussão sobre o tema abordado no GT08 - Formação de Professores e GT12 - Currículo, apontando uma lacuna na exploração de temas relacionados ao currículo do curso de Licenciatura em Matemática e formação de professores, prejudicando o avanço e as inovações no campo educacional.

Contudo, fica em aberto uma discussão para a necessidade do aumento de pesquisas sobre o currículo do curso de Licenciatura em Matemática e formação de professores, e esperamos que questões e reflexões surjam desse trabalho, oportunizando um campo de pesquisa que ampare a prática educacional. 


\section{AGRADECIMENTOS}

Fundação de Amparo à Pesquisa de Minas Gerais - FAPEMIG.

\section{REFERÊNCIAS}

BRASIL. Ministério da Educação e Cultura. Lei n. 9.394/96 de 20 de dezembro de 1996. Diretrizes e Bases da Educação. LDB, 1996.

BRASIL. Secretaria de Educação Fundamental. Parâmetros Curriculares Nacionais: Matemática. Brasília: MEC/SEF, 1997.

CARNEIRO, Reginaldo Fernando. Narrativas no estágio supervisionado em matemática como uma possibilidade para discussão da profissão docente. In. $37^{\circ}$ REUNIÃO ANUAL DA ANPED, 37, 2015, p. 1-17. Florianópolis-SC, 2015. Disponível em:

$<$ http://37reuniao.anped.org.br/wp-content/uploads/2015/02/Trabalho-GT19-3788.pdf $>$. Acesso em: 05/04/2017.

COSTA, Váldina Gonçalves da. Somos uma geração que tem sede de viver as oportunidades, mas se nós não paramos, a vida nos faz parar: A história da constituição de Ana como formadora de professores de matemática. In 33 REUNIÃO ANUAL DA ANPED, 33, 2010, p. 1-16. Caxambu/MG, 2010. Disponível em: $<$ http://33reuniao.anped.org.br/33encontro/app/webroot/files/file/Trabalhos\%20em\%20P DF/GT19-6941--Int.pdf>. Acesso em: 05/04/2017

DIEHL, Astor Antonio. Pesquisa em ciências sociais aplicadas: métodos e técnicas. São Paulo: Prentice Hall, 2004.

Feldmann, Marina Graziela; MASETTO, MarcosTarciso; FREITAS, Silvana Alves.

Formação Inicial de Educadores: currículo, trabalho pedagógico e inovação. In Revista eCurriculum(PUCSP), v. 14, p. 1130-1150, 2016.

FERREIRA, Ana Cristina. A formação de professores de matemática em Minas Gerais: $\mathrm{O}$ caso da Faculdade de Filosofia, Ciências e Letras de Minas Gerais. In $33^{\circ}$ REUNIÃO ANUAL DA ANPED, 33, 2010, p. 1-16. Caxambu/MG, 2010. Disponível em: $<$ http://33reuniao.anped.org.br/33encontro/app/webroot/files/file/Trabalhos\%20em\%20PDF/ GT19-6736--Int.pdf>. Acesso em: 05/04/2017. 
FERREIRA, Viviane Lovatti; PASSOS, LaurizeteFerragut. O percurso histórico da metodologia do ensino de matemática no curso de Pedagogia. In $36^{\circ}$ REUNIÃO ANUAL DA ANPED, 36, 2013, p. 1-16. Goiânia/GO, 2013. Disponível em:

$<$ http://36reuniao.anped.org.br/pdfs_trabalhos_aprovados/gt19_trabalhos_pdfs/gt19_2762_te xto.pdf>. Acesso em: 08/04/2017.

FREIRE, Paulo. Pedagogia da autonomia: saberes necessários à prática educativa. 25. ed. São Paulo: Paz e Terra, 1996. (Coleção leitura).

FREITAS, Adriano Vargas. Educação Matemática e Educação de Jovens e Adultos: estado da arte de publicações em periódicos (2000 a 2010). Tese (Doutorado em Educação Matemática) - Programa de Estudos Pós-Graduados em Educação Matemática, Pontifícia Universidade Católica de São Paulo. São Paulo. 2013.

FREITAS, Silvana Alves. Formação inicial de pedagogas(os) para a concepção e gestão do currículo. 2016. Tese (Doutorado em Educação: Currículo) - Pontifícia Universidade Católica de São Paulo - (PUC-SP), São Paulo, 2016.

LOPES, Celi Espasandin; COUTINHO, Cileda de Queiroz e Silva; ALMOULOUD, Saddo Ag. Estudos e reflexões em Educação Estatística. Campinas: Ed. Mercado de Letras, 2010. MASETTO, Marcos Tarciso. PBL na Educação? In: XII ENCONTRO NACIONAL DE DIDÁTICA E PRÁTICAS DE ENSINO. Anais. Curitiba: PUC/PR 2004, p. 181-189. MASETTO, Marcos Tarciso; ZUKOWSKI-TAVARES, Cristina. Inovação Curricular em Cursos Universitários. In: XI Colóquio sobre Questões Curriculares VII Colóquio Luso Brasileiro sobre Questões Curriculares. Currículo na Contemporaneidade. Braga - Portugal, 2014.

MUNIZ, Cristiano Alberto; COSTA, Edilene Simões; SILVA, Erondina Barbosa da; CARVALHO, Rosália Policarpo Fagundes de; BACCARIN, Sandra Aparecida de Oliveira. Professora Nilza EigenheerBertoni: Sua contribuição para o desenvolvimento da educação matemática no Distrito Federal e no Brasil. In $32^{\circ}$ REUNIÃO ANUAL DA ANPED, 32 , 2009, p. 1-15. Caxambu/MG, 2009.Disponível em:

$<$ http://32reuniao.anped.org.br/arquivos/trabalhos/GT19-5778--Int.pdf $>$. Acesso em: 08/04/2017.

OLIVEIRA, Ana Teresa de Carvalho Correa; FIORENTINI, Dario. O papel e o lugar da didática específica na formação inicial do professor de matemática. $37^{\circ}$ REUNIÃO 
ANUAL DA ANPED, 37, 2015, p. 1-17. Caxambu/MG, 2015.Disponível em:

$<$ http://37reuniao.anped.org.br/wp-content/uploads/2015/02/Trabalho-GT19-4183.pdf $>$.

Acesso em: 05/04/2017

SMOLE, Katia Stocco; DINIZ, Maria Ignez. Ler, escrever e resolver problemas:

habilidades básicas para aprender Matemática. Porto Alegre: Artmed Editora, 2001.

RESENDE, Marilene Ribeiro. Re-significando a disciplina Teoria dos Números na

formação do professor de matemática na Licenciatura. $30^{\circ}$ REUNIÃO ANUAL DA

ANPED, 30, 2007, p. 1-17. Caxambu/MG, 2007. Disponível em:

$<$ http://30reuniao.anped.org.br/trabalhos/GT19-3302--Int.pdf $>$. Acesso em: 08/04/2017.

TEIXEIRA, Célia Regina. O “estado da arte”: a concepção de avaliação educacional

veiculada na produção acadêmica do programa de pós-graduação em educação: currículo

(1975-2000). Caderno de Pós-Graduação: educação, São Paulo, v. 5, n. 1, p. 59-66, 2006. 